and $45.6 \%$ above $0.15 \mathrm{~g} / 100 \mathrm{ml}$. The odd-ratio of traffic injury for patients who drank alcohol within $6 \mathrm{~h}$ prior to injury was 8.5 (95\% CI 5.34 to 13.51) and this followed a clear dose-response relationship. There was no significant difference between the two groups of men in perceptions toward drink-driving. Most respondents over-estimated the number of drinks they could consume in $1 \mathrm{~h}$ to drive safely and legally and most had never planned to avoid driving after drinking. Most men experienced peer approval for drink-driving while very few perceived risk of detection by the police.

Conclusion Programs to raise community awareness and effective legal enforcement are necessary and urgent in Vietnam.

\title{
0970 DRINK-DRIVING IN VIETNAM: PERCEPTIONS AND RISK
}

TM Nguyen* Correspondence: Hue College of Medicine and Pharmacy, 6 Ngo Quyen Street, Hue City, Vietnam

\subsection{6/ip.2010.029215.970}

Rapidly increasing motorisation and an expanding alcohol industry in Vietnam have placed traffic injury among the leading causes of death. However, there is little local research into the specific contribution of alcohol to this burden and the socio-cultural contexts of drink driving.

Objectives (1) To measure alcohol intoxication of male patrons in restaurants and males with traffic-related injuries at an Emergency Department, (2) To estimate risk of traffic injury after acute alcohol consumption using case-crossover analysis, and (3) To compare perceptions toward drink-driving of injured and uninjured males.

Methods Male patrons at seven restaurants $(n=464)$ and men admitted to hospital following traffic injuries $(n=480)$ were interviewed and measured for blood alcohol concentration (BAC) by a breathalyzer.

Results Among the uninjured restaurant patrons, 76.6\% had a BAC over the legal limit $(0.08 \mathrm{~g} / 100 \mathrm{ml})$ and $39.7 \%$ were above $0.15 \mathrm{~g} / 100 \mathrm{ml}$. Among patients, $57.5 \%$ were over $0.08 \mathrm{~g} / 100 \mathrm{ml}$ 